\title{
Issues and Limitations of Broad Band Remote Sensing of Kimberlite-A Case Example from Kimberlites of Dharwar Craton, India
}

\author{
Arindam Guha ${ }^{1 *}$, S. Ravi ${ }^{2}$, D. Ananth Rao ${ }^{1}$, K. Vinod Kumar ${ }^{1}$, E. N. Dhananjaya Rao ${ }^{3}$ \\ ${ }^{1}$ Geosciences Division, National Remote Sensing Centre, Indian Space Research Organization, Hyderabad, India \\ ${ }^{2}$ Geological Survey of India, Hyderabad, India \\ ${ }^{3}$ Department of Geology, Andhra University, Visakhapatnam, India \\ Email: *arindamisro@gmail.com
}

Received October 26, 2012; revised December 1, 2012; accepted January 2, 2013

\begin{abstract}
Present study attempts to understand the potential of multispectral ASTER (Advanced space borne thermal emission and reflection radiometer) data for spatial mapping of kimberlite. Kimberlite is an economic rock known for hosting diamond. Kimberlite also has petrogenetic importance for giving us clue on the composition of lower part of the mantle. Kimberlites often contain serpentine, carbonate minerals; which have their diagnostic spectral signatures in short wave infrared (SWIR) domain. In the present study, attempt is made to delineate kimberlite from adjacent granite-granodiorite gneiss based on processing of the ASTER data as ASTER's spectral channels can detect some of the diagnostic absorption features of kimberlites. But it has been observed that the kimberlites are difficult to be delineated by processing the ASTER data using correlative information of both sub-pixel and per-pixel mapping. Moreover, smaller spatial size of kimberlites with respect to pixel size of ASTER SWIR channels further obscures the spectral feature of kimberlite. Therefore, an attempt is also made to understand how intra pixel spectral mixing of kimberlite and granite granodiorite-gneiss modifies the diagnostic spectral feature of kimberlite. It is observed that spectral feature of kimberlites would be obscured when it is has very small spatial size (one-tenth of pixel) with respect to pixel size. Moreover, calcrete developed in the adjacent soil has identical absorption feature similar to the spectral features of kimberlites imprinted in the respective ASTER convolved spectral profiles. This also has resulted false-positives in ASTER image when we use spectral feature as a tool for spatial mapping of kimberlite. Therefore hyperspectral data with high spatial and spectral resolution is required for targeting kimberlites instead of using broad band spectral feature of kimberlites.
\end{abstract}

Keywords: ASTER; Short-Wave-Infrared Channel; Per-Pixel; Sub Pixel Mapping; False Positives; Calcretes

\section{Introduction}

Reflectance spectroscopy is a branch of spectroscopy mainly study the change in reflectance across the electromagnetic wavelength region of spectral data collection [1]. Absorption dip or absorption feature imprinted in the reflectance spectra is indicative of atomic process related to atomic structure of minerals [1,2]. Therefore reflectance spectroscopy has become a potentially important tool for spatial mapping of the minerals. Another important advantage of reflectance spectra is that it can record mineralogy irrespective of the distance between target and sensor [1]. Therefore space borne/airborne sensors are often used to map mineralogy from space [3-12]. Delineation of kimberlite pipe is an important step for diamond exploration. In general, conventional exploration methods, such as indicator minerals survey, field

${ }^{*}$ Corresponding author. based systematic mapping, are used for discovering kimberlite pipes [13-15]. Satellite data are also used in narrowing down the search of pipe based on mapping of lineaments and their intersections suitable for kimberlite emplacement. Another way of getting the indication of kimberlites is to delineate the surface signature of pipes based on their spectral characters. Some research initiatives were made earlier to map kimberlite based on spectral feature of its constituent minerals like antigorite etc. [16]. ASTER data has appropriate band for detecting spectral features of mineral like serpentine and calcite. Serpentine minerals and calcite have spectral feature at 2.32 and 2.34 micrometer respectively $[17,18]$. Launch of ASTER sensor in the NASA's Terra satellite in 1999 has provided the remote sensing community multispectral data in SWIR domain capable of mapping minerals [19]. Different alteration minerals associated with hydrothermal deposits and rocks like limestone and bauxites 
are also mapped by using the broad absorption features recorded in the ASTER data [20-23].

Moreover recent studies have demonstrated that spectral features of different kimberlites are distinct and can be subdivided in few types based on the presence of minerals like calcite, serpentine group of minerals and olivine [24], Recent study also has demonstrated the fact that the wavelength of absorption of diagnostic spectral features of kimberlites of specific type (carbonate rich, serpentine rich etc.) remain consistent irrespective of grain size variations and variations in the measurement set up (with respect to change in phase angle and distance between measurement optics and surface of the sample or target) for spectral profile collection [24]. This observation is important with regard to mapping of kimberlite in spatial domain using spectral feature of kimberlite spectra as end member.

In present study, spectral profiles of kimberlites are collected and convolved to ASTER band width for processing ASTER data for mapping kimberlite. In present case, effort is made to understand broad ASTER derived spectral profiles of kimberlites and associated rocks for spatial of mapping of kimberlites. Moreover, image spectra of kimberlites and ASTER convolved laboratory spectra of kimberlites both are used for spatial mapping of the kimberlite in ASTER data.

\section{Study Area}

The study area is situated at the north-western part of Andhrapradesh state of India and bounded by the latitude from $16^{\circ} 44^{\prime}$ to $16^{\circ} 51^{\prime}$ and longitude from $77^{\circ} 35^{\prime}$ to $77^{\circ} 42^{\prime}$. Kimberlites of this area is known by the name of nearest town known Narayanpet (Figure 1). The mineral assemblages and textures of kimberlite-pipes indicate that these bodies correspond to hypabyssal facies or root zone facies of the kimberlites. Narayanpet kimberlite field (NKF) is one of the major kimberlite field of Dharwar craton and occurring at the eastern part of Dharwar craton. The NKF Kimberlites, in general, are very small bodies and these kimberlites lack mantle xenoliths [25]. Narayanpet kimberlites are emplaced in granodiorites and gneisses and structurally controlled by E-W and NE-SW trending lineament [15]. The kimberlites pipe studied here have

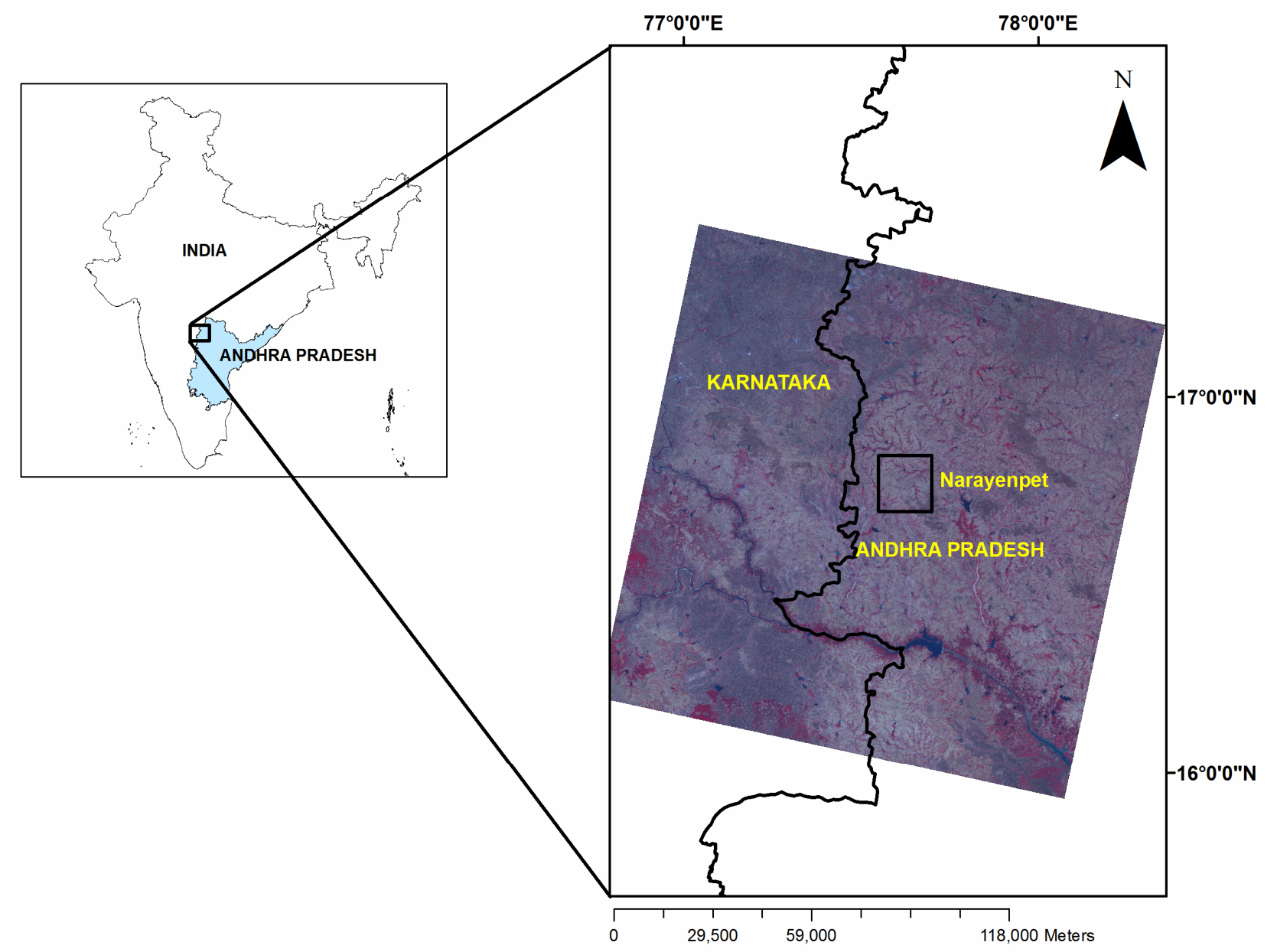

Figure 1. Location map of the study area. 
been subdivided in three major types-serpentine rich, olivine rich and carbonate rich based on the predominant mineral in respective kimberlite pipe.

\section{Data}

A STER level-1B data is used for the purpose of the present study. ASTER Level-1B data is “at-sensor" radiance data with the geometric correction applied to the data and visible near infrared (VNIR) and shortwave infrared (SWIR) channels are co-registered to each other. ASTER data; especially SWIR bands have shown significant potential in detecting minerals and rocks and therefore reflection data products is increasingly used to map rocks and minerals in inaccessible areas. The broad specification of ASTER visible-near-infrared and shortwave infrared (VNIR-SWIR) bands of ASTER have been provided in the Table 1 [19].

\section{Methodology}

\subsection{Spectral Profile Collection}

Kimberlite samples are collected from different places of the study area and the rock samples are cut into sizes of 3 inch $\times 5$ inch to 5 inch $\times 7$ inch. Surfaces of samples are polished to remove the unevenness but the surface weathering characteristics are preserved. Spectral profiles are collected in the controlled environment using Fieldspec 3 spectrora-diometer. The details of methodology for collecting rock spectra have been already discussed in the published literature [24,26].

\subsection{Pre-Processing}

Log residual correction is used to derive relative reflectance image from georeferenced radiance image (ASTER level $1 \mathrm{~B}$ data). Log residual correction is effective in removing solar irradiance, atmospheric transmittance, instrument gain, topographic effects and albedo effects from radiance data [27]. The pseudo reflectance image derived by using log residual atmospheric algorithm is based on the mathematical approach wherein the input radiance spectrum is divided by spectral geometric mean followed by spatial geometric mean of radiance spectra of each band for a particular pixel and all the pixels of each band, respectively [27]. After the log residual calibration, data is further rescaled by using a scalar factor derived from the ratio of image and laboratory spectra of granite-granodiorite-gneiss, which have homogeneous exposures and are well delineated in the ASTER image.

\subsection{End Member Selection}

Spectral features imprinted in the respective spectral profiles of different types of kimberlite are the basis for processing the ASTER data (Figure 2). Here, ASTER data is processed to understand how the spectral features of different types of kimberlite can be used to spatially delineate kimberlites in ASTER data. For this reason, laboratory spectra of kimberlites are convolved to ASTER-SWIR bandwidth. For delineating kimberlites from granite-granodiorite-gneiss, only six short-wave infrared (SWIR) channels of ASTER data are used as kimberlites have diagnostic spectral features within this domain (Figure 3).

It has been observed from the analysis of ASTER convolved laboratory spectral profiles of different types of kimberlites, that the both carbonate rich and serpentine rich kimberlite pipes have absorption feature at 8th band of ASTER data (Figure 3). On the other hand, olivine rich kimberlite is devoid of significant absorption feature and is characterised with a subtle absorption feature with wavelength of absorption at $1093 \mathrm{~nm}$ (1.093 micrometer)

Table 1. The specification of ASTER data (VNIR-SWIR domain).

\begin{tabular}{|c|c|c|c|c|c|}
\hline Satellite Data & Data Product & Spectral Bands & $\begin{array}{c}\text { Spectral Range } \\
(\mu \mathrm{m})\end{array}$ & $\begin{array}{c}\text { Spatial Resolution } \\
\text { Meter (m) }\end{array}$ & $\begin{array}{c}\text { Radiometric Resolution } \\
\text { (Bit) }\end{array}$ \\
\hline \multirow{9}{*}{ ASTER Data } & \multirow{3}{*}{ VNIR } & 1 & $0.5-0.60$ & 15 & 8 \\
\hline & & $3 N$ & $0.78-0.86$ & 15 & 8 \\
\hline & & $3 B$ & $0.78-0.86$ & 15 & 8 \\
\hline & \multirow{6}{*}{ SWIR } & 4 & $1.60-1.70$ & 30 & 8 \\
\hline & & 5 & $2.145-2.185$ & 30 & 8 \\
\hline & & 6 & $2.185-2.225$ & 30 & 8 \\
\hline & & 7 & $2.235-2.285$ & 30 & 8 \\
\hline & & 8 & $2.295-2.365$ & 30 & 8 \\
\hline & & 9 & $2.360-2.430$ & 30 & 8 \\
\hline
\end{tabular}




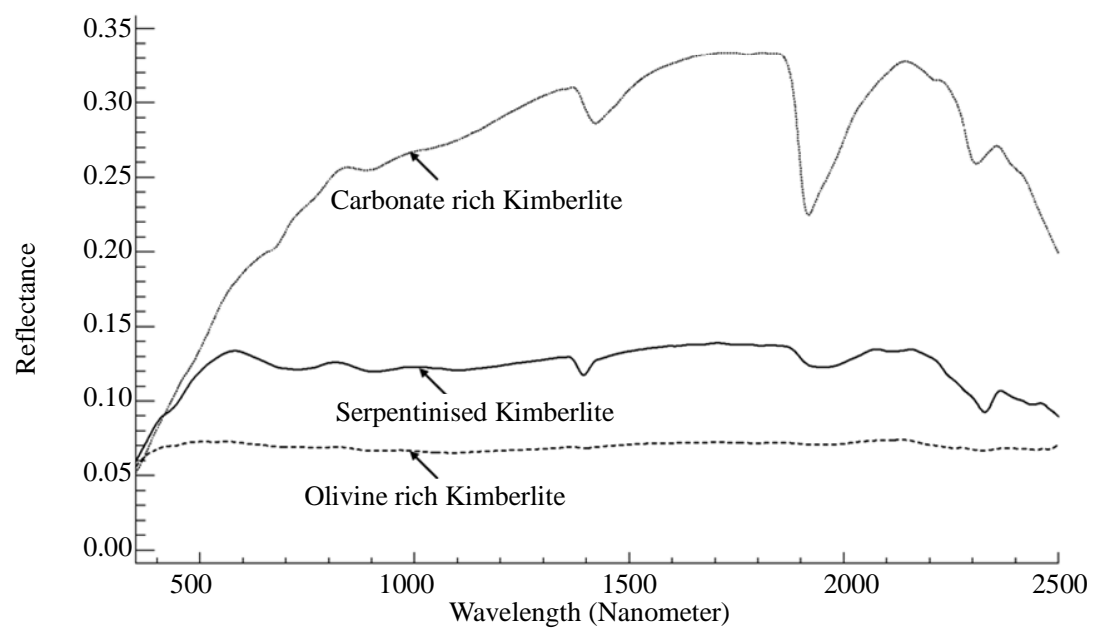

Figure 2. Laboratory spectra of different types of kimberlites of the study area.

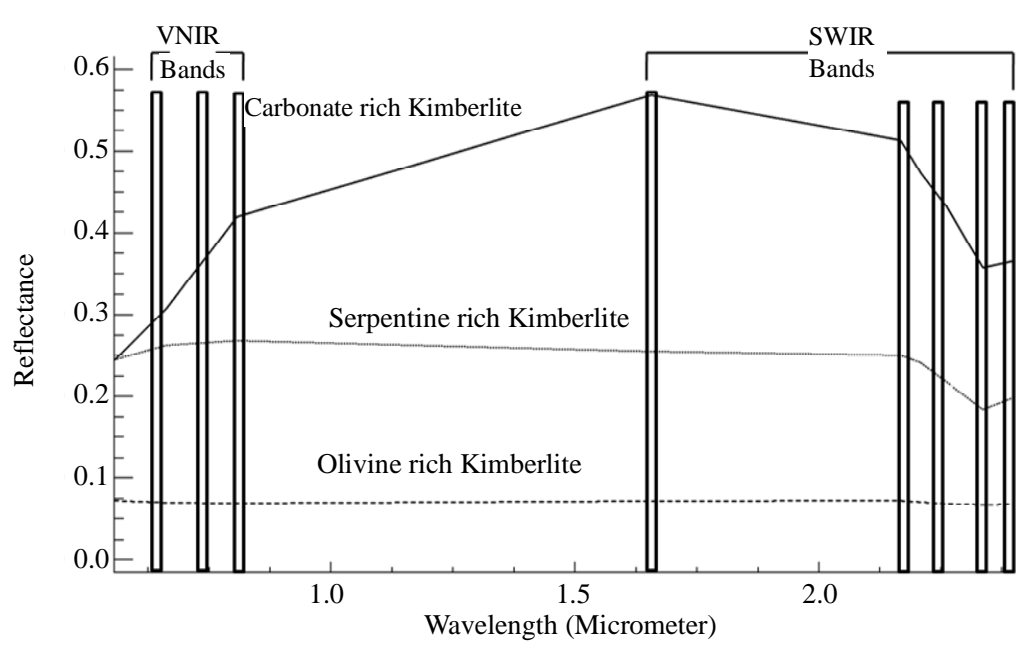

Figure 3. ASTER convolved laboratory spectral profiles of different types of kimberlites. Absorption features of carbonate and serpentine rich kimberlite are recorded at 8th channel (Central wavelength: 2.33 micrometer). Position of ASTER VNIR-SWIR bands are also schematically shown.

which cannot be recorded by any ASTER channel as ASTER does not have any corresponding band within this electromagnetic domain. Therefore, absorption feature of ASTER convolved laboratory spectral profiles of carbonate rich and serpentine rich kimberlites are used to map kimberlite based on using partial unmixing algorithm.

In addition to above, image spectra is also collected from the known exposure location of kimberlite and granite-granodiorite gneiss. While analysing the pixel spectra of kimberlite and associated granodiorite gneiss, it has been understood that associated granodiorite gneiss has absorption at $2.2 \mu \mathrm{m}$ whereas kimberlites have absorption at $2.33 \mu \mathrm{m}$ and therefore this broad spectral variability can be used to separate kimberlites from granite-granodiorites-gneiss based on deriving an index image highlighting afore-mentioned spectral response of pixels containing kimberlite (Figure 4).

\subsection{Spatial Mapping of Kimberlite}

Laboratory spectral profiles of different types of kimberlite are varied from each other in terms of absorption features imprinted in their respective reflectance spectra (Figure 2). Serpentinised and carbonate rich kimberlite have their absorption feature at 2325 and $2300 \mathrm{~nm}$ (Figure 2) resulted due to serpentine and carbonate (i.e.) minerals respectively [1,17]. However, wavelength of absorption of diagnostic mineral is shifted along the wavelength axis in rock spectra with respect to same absorption feature imprinted in respective mineral spectra. ASTER convolved laboratory spectra of these kimberlites have preserved the spectral features of laboratory spectra of these pipes but in generalised way (Figure 3). However, the ASTER convolved spectral profile of olivine rich kimberlite is featureless (Figure 3). Further, laboratory spectral profiles of kimberlites are convolved to ASTER bandwidth of 


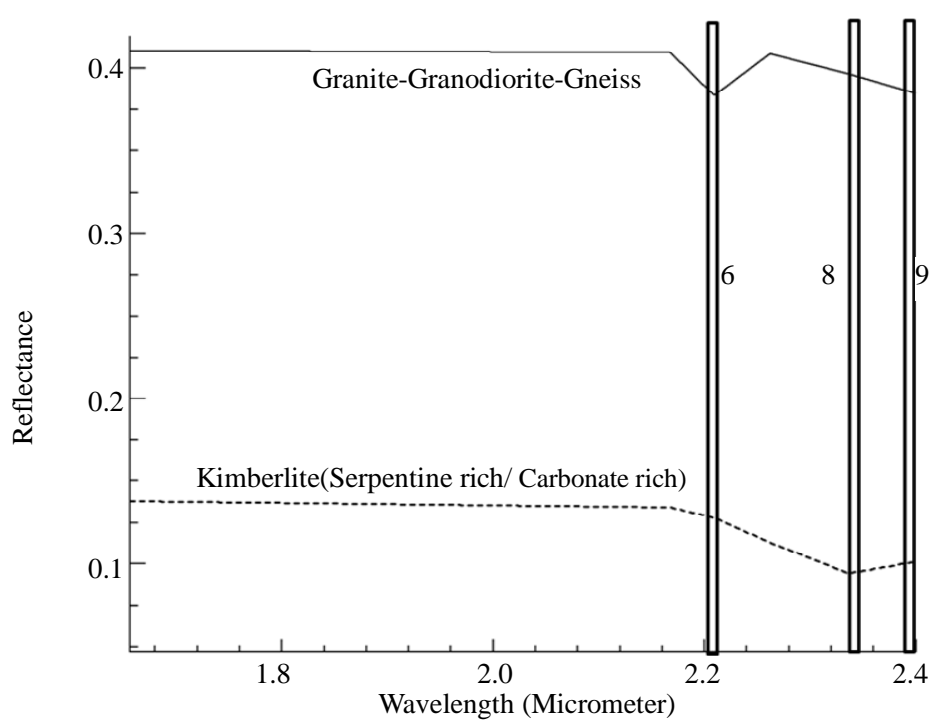

Figure 4. Broad spectral differences of kimberlite and granite granodiorite gneiss are observed ASTER SWIR image derived spectra of respective lithovariants. The position of ASTER channel used for deriving index image is also shown schematically on these spectra.

SWIR channels for spatial mapping of kimberlite using sub pixel algorithm as the exposures of Narayanpet kimberlites are very small in size in comparison to the pixel size of ASTER data [25]. As the ASTER convolved laboratory spectral profiles of serpentinised and carbonate rich kimberlites are characterised with an absorption feature at around 2.33 micrometer (Figure 3); hence, mean of ASTER convolved spectral profile carbonate and serpentine-rich kimberlite is used as a single end member for targeting the kimberlite based on sub-pixel mapping algorithm (Figure 3). In this respect, matched filtering algorithm is used to supplement the result of the index image delineating kimberlites. Match filtering is a mapping method used to delineate target from background based on the mean of the data-matrix. Further, based on the input target spectra and synthesised background spectra, each pixel spectra is unmixed to target and background. Match filtering is a efficient sub-pixel mapping method for suppressing the response of composite back ground for rapid mapping of target based on the spectral feature of endemeber $[27,28]$. The match filtering value of output image is indicative of the relative dominance of the target within the pixel in terms of abundance.

Keeping in view the spectral feature of kimberlite pixel in VNIR-SWIR image of ASTER image, an index image is derived by using 6,8,9 bands of ASTER. As per the image spectra of kimberlite, band 6,9 (3rd and 6th SWIR channel) are located at the shoulder of diagnostic spectral feature of kimberlites whereas 8th band (5th SWIR band) captures absorption minima of diagnostic feature for both serpentine and carbonate rich kimberlites (Figure 4). As the pixel-spectra of carbonate and serpentine rich kimberlites are generalised with similar spectral features in the broad spectral bandwidth of ASTER channels; therefore same indices are used for detecting both types of pipes using the index image derived based on the pixel spectra of kimberlite.

\section{Results}

We have attempted sub-pixel mapping technique in which we have used ASTER convolved laboratory spectra for delineating kimberlites. In addition, we have also attempted a per pixel mapping technique (band-ratio), where image spectra of kimberlite pixel is used for deriving the ratio image. In both images, we have detected widely distributed pixels indicative of kimberlite. Therefore, we have attempted to reduce the wide distribution of target pixels indicative of kimberlite as kimberlite distribution is restricted in the study area. In this regard, the results of sub pixel and per pixel mapping of spatial distribution of kimberlite derived based on spectral signatures are effectively combined using correlation of ratio and match filtering value of respective per-pixel and sub-pixel map products. Pixels with high index value and match filtering value are shown with red colour. The known kimberlite pipes are in congruence with the surface signatures. However, the pixels indicating spectral feature of kimberlite is still widely distributed (Figure 5).

\section{Discussion and Conclusions}

It has been observed that anomalous pixels characterizing kimberlites are widely spread in comparison to restricted spatial extent of known kimberlite pipes. This over esti- 
mation of the extent of spatial distribution of kimberlites is due to the fact that generalised spectra of kimberlites may have similarity with other terrain elements. Calcretes are formed over kimberlites and often are randomly distributed over wider spatial extent based on topographic setup of the area. Calcretes are spectrally similar with kimberlites in terms of wavelength of absorption feature. This has been evident from the comparison of ASTER convolved spectral feature of calcrete and kimberlites (Figure 6). Few spectral channels of ASTER are not suitable to delineate spectrally similar features; which have closely spaced diagnostic feature in terms of wavelength of absorption (i.e. when absorption minima of two different spectral features are 10 - $20 \mathrm{~nm}$ apart; then these features would be alike in broad multispectral band).

Moreover, kimberlites are known for sparse or small exposures. Therefore subtle spectral features of kimberlites would often get suppressed/subdued due to intra pixel mixing with terrain elements. The size of the exposures of kimberlites of the study area, are small with di- ameter up to few meters [15]; therefore there is high possibility that the kimberlite would be mixed with other terrain elements within the spatial extent of ASTER SWIR channel (i.e. 30 meter). In order to understand the role of intra pixel spectral mixing, ASTER convolved spectral profiles of mixed-pixels containing the kimberlite are modelled based on the concept of weighted linear mixing using ASTER convolved spectral profiles of kimberlites and adjacent granite-granodiorite gneiss in different proportion. Further, ASTER convolved mixed spectra of kimberlites are compared with the granite/granodioritegneiss spectra and it has been found that kimberlite bearing pixel spectra with $20 \%$ of the pixel occupied by kimberlite (3 - 4 meter in size) would be totally suppressed as diagnostic spectral feature of kimberlite at $2.33 \mu \mathrm{m}$ would be obscured and hence can not be spectrally separated from the associated granodiorite/granitegneiss (Figure 7). Therefore, due to the possibility of intrapixel mixing of kimberlite spectra, with the spectra of adjacent rock and also, due to similar spectral re-

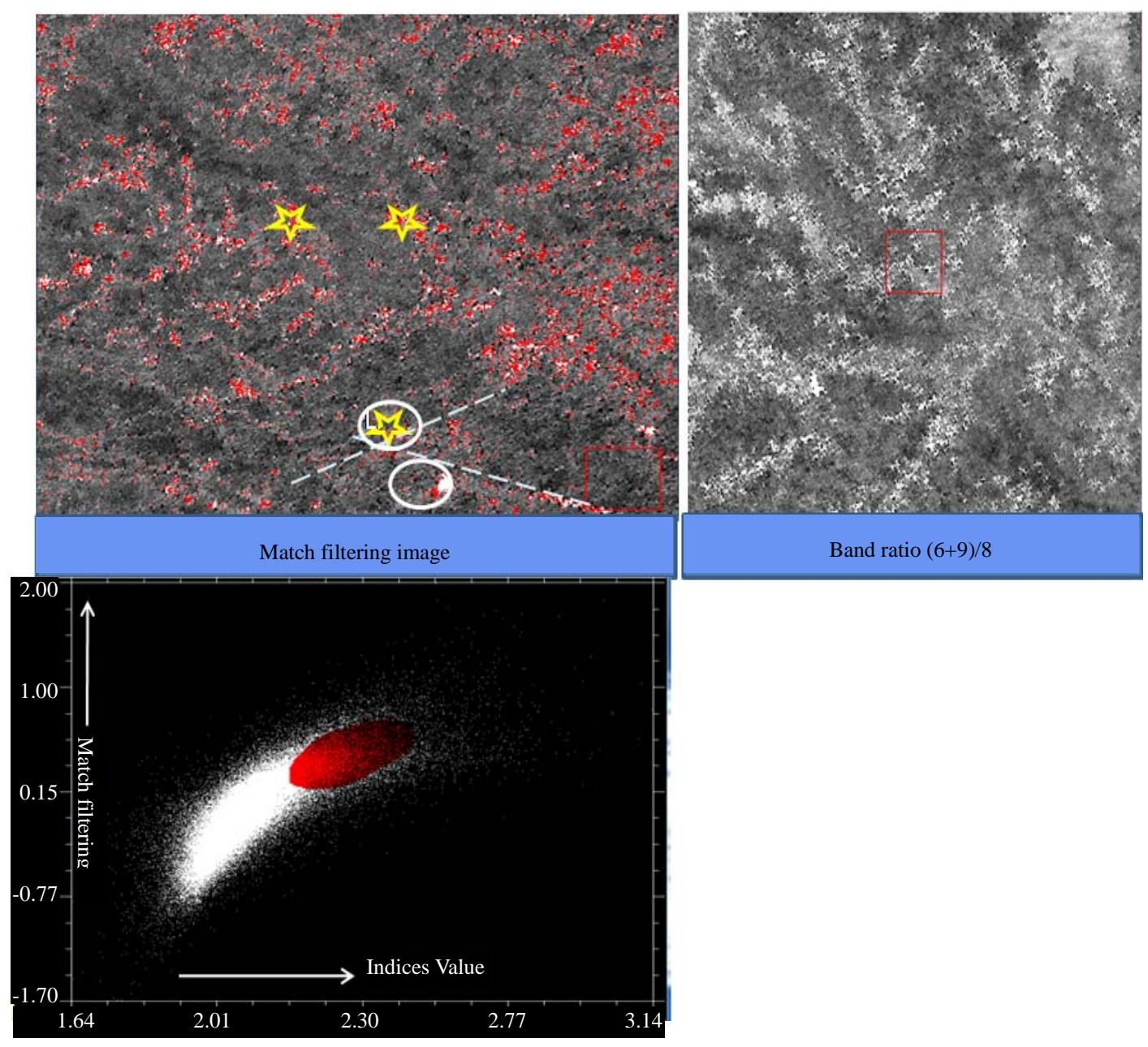

Figure 5. Delineation of spatial distribution (highlighted by red-coloured pixel in match filtering image) of kimberlites and associated calcretes (known kimberlite locations are shown with asterisk). 


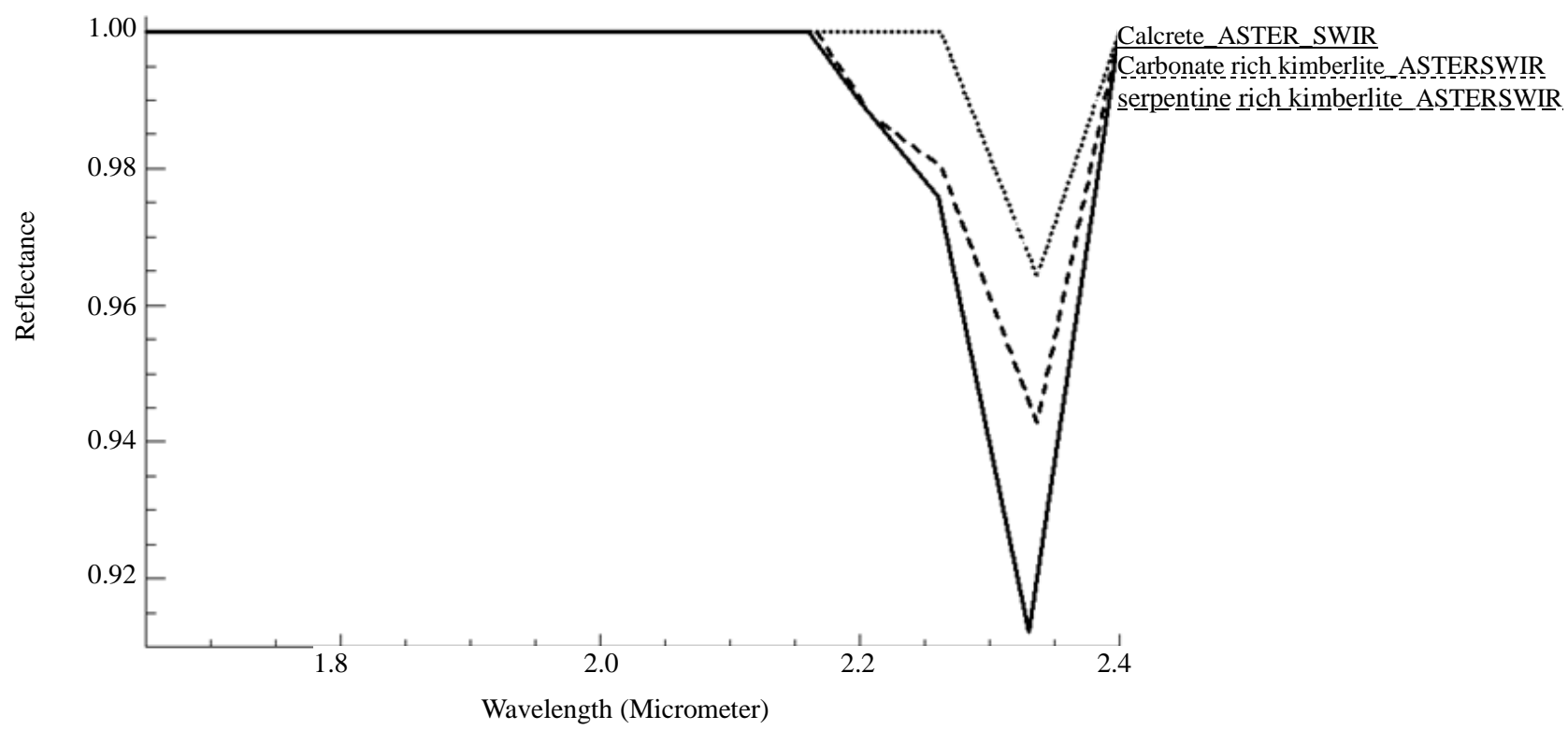

Figure 6. ASTER SWIR image derived spectra of calcrete, serpentinised and carbonate rich kimberlite showing same absorption features in terms of wavelength of absorption for these three different terrain elements.

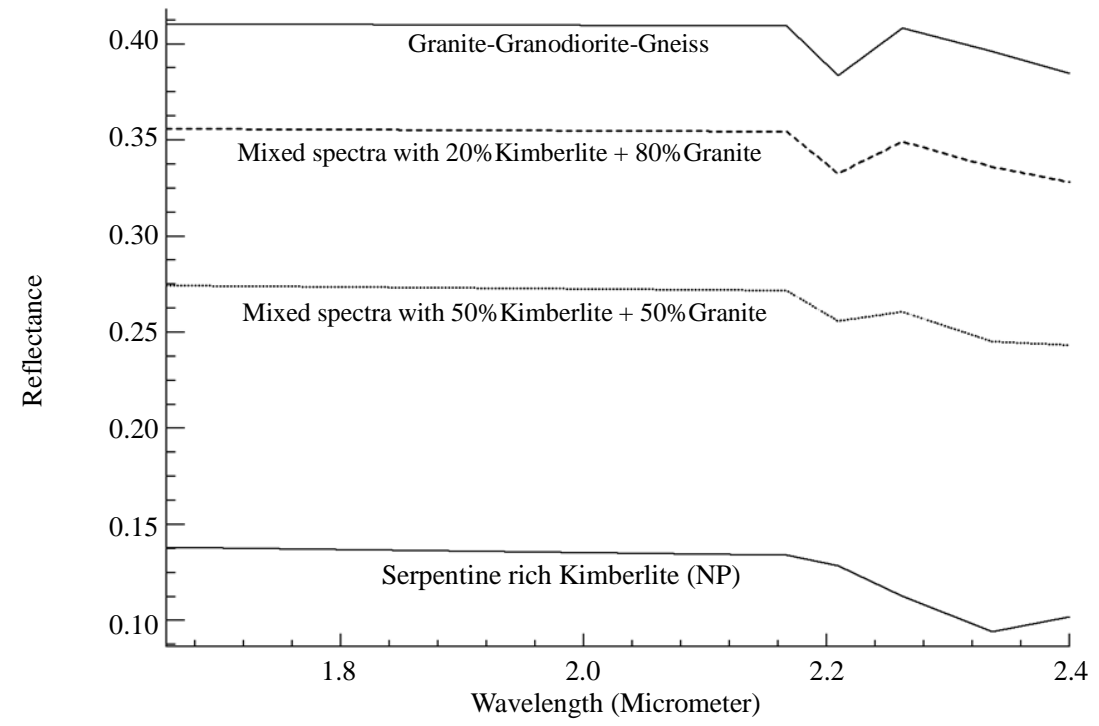

Figure 7. Illustration on the effect of spectral modelling for understanding the mixed-pixel spectral response (input spectra of serpentine rich kimberlite and granite/gneiss spectra are ASTER convolved laboratory spectra).

sponses of widely distributed calcretes in ASTER bands; delineation of kimberlites will be difficult in multispectral ASTER data, despite the fact that ASTER data has the spectral band suitable for recording absorption feature of kimberlite.

Hence, hyperspectral data with high spectral and spatial resolution (10 - $20 \mathrm{~nm}$ in terms of spectral resolution and $4 \mathrm{~m}$ in terms of spatial resolution) with appreciable SNR (signal-to noise ratio) should be used for mapping target like kimberlites, which have subdued and narrow diagnostic absorption signatures (Figure 2). However, kimberlites are emplaced in this area are associated with WNW-ESE and NE-SW trending faults [15]; therefore spectrally anomalous zones (demarcated as red in colour in Figure 5) if associated these lineaments can be regarded as more promising areas for kimberlite occurrence (Figure 5).

\section{Acknowledgements}

We thank Dr. V. K. Dadhwal, Director, NRSC for his 
guidance, support and for sanctioning the grant for publishing the paper. We also thank Dr. V. Ragahavasamy, Deputy Director (RSA) for his supervision and support. We are also thankful to anonymous reviewer for constructive suggestive correction.

\section{REFERENCES}

[1] R. N. Clark, "Spectroscopy of Rocks and Minerals, and Principles of Spectroscopy,” 2011. http://speclab.cr.usgs.gov/PAPERS.refl-mrs/refl4.html

[2] E. A. Cloutis, "Hyperspectral Geological Remote Sensing: Evaluation of Analytical Techniques," International Journal of Remote Sensing, 1996, Vol. 17, No. 12, pp. 22152242. doi:10.1080/01431169608948770

[3] R. N. Clark, T. V. V. King, M. Klejwa, G. Swayze and N. Vergo, "High Spectral Resolution Reflectance Spectroscopy of Minerals,” Journal of Geophysical Research, Vol. 95, 1990, pp. 12653-12680.

[4] R. N. Clark and T. L. Roush, "Reflectance Spectroscopy: Quantitative Analysis Techniques for Remote Sensing Applications,” Journal of Geophysical Research, Vol. 89, 1984, pp. 6329-6340.

[5] E. A. Cloutis, F. C. Hawthorne, S. A. Mertzman, K. Krenn, M. A. Craig, D. Marcino, M. Methot, J. Strong, J. F. Mustard, D. L. Blaney, J. F. Bell III and F. Vilas, "Detection and Discrimination of Sulfate Minerals Using Reflectance Spectroscopy,” Icarus, Vol. 184, No. 1, 2006, pp. 121-157.

[6] A. B. Pour and M. Hashim, "Identifying Areas of High Economic-Potential Copper Mineralization Using ASTER Data in the Urumieh-Dokhtar Volcanic Belt," Advances in Space Research, Vol. 49, No. 4, 2012, pp. 753-769.

[7] L. S. Galvao, R. Almeida-Filho and Í. Vitorello, "Spectral Discrimination of Hydrothermally Altered Materials Using ASTER Short-Wave Infrared Bands: Evaluation in a Tropical Savannah Environment,” International Journal of Applied Earth Observation and Geoinformation, Vol. 7, No. 2, 2005, pp. 107-114. doi:10.1016/j.jag.2004.12.003

[8] F. Van der Meer, "Can We Map Swelling Clays with Remote Sensing?” Jouranl of Applied Earth Observation and Geoinformatics, Vol. 1, No. 1, 1999, pp. 27-35.

[9] F. J. A. van Ruitenbeek, P. Debba, F. D. van der Meer, T. Cudahy, M. van der Meijde and M. Hale, "Mapping White Micas and Their Absorption Wavelengths Using Hyperspectral Band Ratios," Remote Sensing of Environment, Vol. 102, 2006, pp. 211-222. doi:10.1016/j.rse.2006.02.012

[10] L. E. Vicente and C. R. de Souza Filho, "Identification of Mineral Components in Tropical Soils Using Reflectance Spectroscopy and Advanced Spaceborne Thermal Emission and Reflection Radiometer (ASTER) Data," Remote Sensing of Environment, Vol. 115, No. 8, 2011, pp. 18241836. doi:10.1016/j.rse.2011.02.023

[11] G. F. Zhang, X. H. Shen, L. J. Zou, C. J. Li, Y. L. Wang and S. L. Lu, "Detection of Hydrocarbon Bearing Sand through Remote Sensing Techniques in the Western Slope Zone of Songliao Basin, China," International Journal of Remote Sensing, Vol. 28, No. 8, 2007, pp. 1819-1833.

\section{doi:10.1080/01431160600975329}

[12] X. Zhang, M. Pazner and N. Duke, "Lithologic and Mineral Information Extraction for Gold Exploration Using ASTER Data in the South Chocolate Mountains (California)," ISPRS Journal of Photogrammetry and Remote Sensing, Vol. 62, No. 4, 2007, pp. 271-282. doi:10.1016/j.isprsjprs.2007.04.004

[13] M. Lynn, “The Discovery of Kimberlites in the Gulbarga and Raichur Districts of Karnataka. Group Discussion on Kimberlites and Related Rocks of India,” Group Discussion on Kimberlites and Related Rocks of India, 2005, pp. 48-49.

[14] D. S. N. Murthy and A. M. Dayal, "Geochemical Characteristics of Kimberlite Rock of the Anantapur and Mahbubnagar Districts, Andhra Pradesh, South India,” Journal of Asian Earth Sciences, Vol. 19, No. 3, 2001, pp. 311-319. doi:10.1016/S1367-9120(00)00014-6

[15] S. Neelakantam, "Exploration for Diamond in Southern India,” Journal of Geological Survey of India, Special Publication, 2001, pp. 521-555.

[16] F. A. Kruse and J. W. Boardman, "Characterization and Mapping of Kimberlites and Related Diatremes Using Hyperspectral Remote Sensing," IEEE Aerospace Conference Proceedings, Big Sky, 18-25 March 2000, pp. 299-304.

[17] S. J. Gaffey, "Spectral Reflectance of Carbonate Minerals in Visible and Near Infrared: Anhydrous Carbonate Minerals,” Journal of Geophysical Research, Vol. 92, No. B2, 1987, pp. 429-1440.

[18] N. Jain, S. Bhattacharya, P. Chauhan and Ajai, "Hyperspectral Study of Hydrous Magnesium Minerals (Serpentine) from Ultramafic Rocks along the Rikhdev Lineament, Rajasthan, India: As an Analogue for Hydrous Magnesium Minerals on Mars," 43rd Lunar and Planetary Science Conference, the woodlands, 19-23 March 2012.

[19] M. Abrams, “The Advanced Spaceborne Thermal Emission and Reflection Radiometer (ASTER): Data Products for the High Spatial Resolution Imager on NASA's Terra Platform,” International Journal of Remote Sensing, Vol. 21, No. 5, 2000, pp. 847-859. doi:10.1080/014311600210326

[20] B. Enton, "Mineral Mapping in the Kap Simpson Complex, Central East Greenland, Using HyMap and ASTER Remote Sensing Data,” Advances in Space Research, Vol. 47, No. 1, 2011, pp. 60-73. doi:10.1016/j.asr.2010.08.021

[21] S. Gad and T. Kusky, “ASTER Spectral Ratioing for Lithological Mapping in the Arabianâ Nubian Shield, the Neoproterozoic Wadi Kid Area, Sinai, Egypt,” Gondwana Research, Vol. 11, No. 3, 2007, pp. 326-335. doi:10.1016/j.gr.2006.02.010

[22] A. Guha, V. K. Singh, R. Parveen, K. Vinod Kumar, A. T. Jeyaseelan and E. N. Dhanamjaya Rao, "Analysis of ASTER Data for Mapping Bauxite Rich Pockets within High Altitude Lateritic Bauxite, Jharkhand, India,” International Journal of Applied Earth Observation and Geoinformation, Vol. 21, 2013, pp. 184-194. doi:10.1016/j.jag.2012.08.003

[23] L. C. Rowan and J. C. Mars, "Lithologic Mapping in the 
Mountain Pass, California Area Using Advanced Spaceborne Thermal Emission and Reflection Radiometer (ASTER) Data,” Remote Sensing of Environment, Vol. 84, No. 3, 2003, pp. 350-366.

doi:10.1016/S0034-4257(02)00127-X

[24] A. Guha, A. Rao, S. Ravi, K. Vinod Kumar and E. N. Dhananjaya Rao, "Analysis of the Potentials of Kimberlite Rock Spectra as Spectral End Member-A Case Study Using Kimberlite Rock Spectra from the Narayanpet Kimberlite Field (NKF), Andhrapradesh," Current Science, Vol. 103, No. 9, 2012, pp. 1096-1104.

[25] N. V. C. Rao, C. Paton and B. Lehmann, "Origin and Diamond Prospectively of Mesoproterozoic Kimberlites from the Narayanpet Field, Eastern Dharwar Craton, Southern India: Insights from Groundmass Mineralogy, BulkChemistry and Perovskite Oxybarometry," Geological
Journal, Vol. 47, No. 2-3, 2012, pp. 186-212. doi:10.1002/gj.1309

[26] A. Guha, D. Chakraborty, A. B. Ekka, K. Pramanik, K. Vinod Kumar, S. Chatterjee, S. K. Subramanium and D. Ananth Rao, "Spectroscopic Study of Rocks of HuttiMaski Schist Belt, Karnataka,” Journal of Geological Society of India, Vol. 79, No. 4, 2012, pp. 335-344.

[27] ENVI 4.8. Help: “Calibration Utilities: Log Residual Correction".

[28] F. Moore, F. Rastmanesh, H. Asadi and S. Modabberi, "Mapping Mineralogical Alteration Using Principal-Component Analysis and Matched Filter Processing in the Takab Area, North-West Iran, from ASTER Data," International Journal of Remote Sensing, Vol. 29, No. 10, 20 May 2008, pp. 2851-2867. 